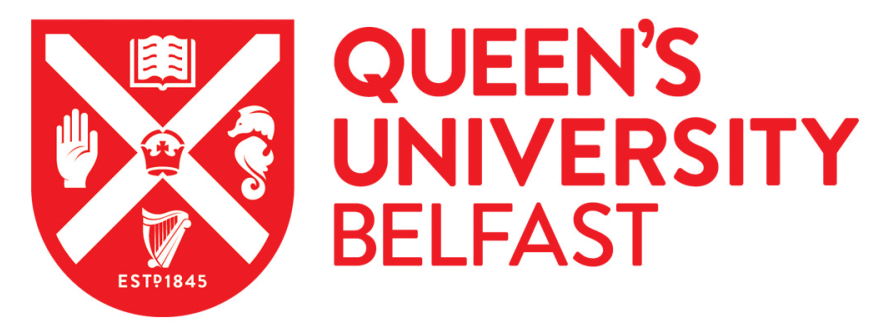

\title{
Experimental demonstration of a compact epithermal neutron source based on a high power laser
}

Mirfayzi, S. R., Alejo, A., Ahmed, H., Raspino, D., Ansell, S., Wilson, L. A., Armstrong, C., Butler, N. M. H., Clarke, R. J., Higginson, A., Kellerher, J., Murphy, C. D., Notley, M., Rusby, D. R., Schooneveld, E., Borghesi, M., McKenna, P., Rhodes, N. J., Neely, D., ... Kar, S. (2017). Experimental demonstration of a compact epithermal neutron source based on a high power laser. Applied Physics Letters, 111(04), 044101-1. [044101-4]. https://doi.org/10.1063/1.4994161

Published in:

Applied Physics Letters

Document Version:

Publisher's PDF, also known as Version of record

Queen's University Belfast - Research Portal:

Link to publication record in Queen's University Belfast Research Portal

Publisher rights

Copyright AlP 2017. This work is made available online in accordance with the publisher's policies. Please refer to any applicable terms of use of the publisher.

\section{General rights}

Copyright for the publications made accessible via the Queen's University Belfast Research Portal is retained by the author(s) and / or other copyright owners and it is a condition of accessing these publications that users recognise and abide by the legal requirements associated with these rights.

Take down policy

The Research Portal is Queen's institutional repository that provides access to Queen's research output. Every effort has been made to ensure that content in the Research Portal does not infringe any person's rights, or applicable UK laws. If you discover content in the Research Portal that you believe breaches copyright or violates any law, please contact openaccess@qub.ac.uk. 


\section{Experimental demonstration of a compact epithermal neutron source based on a high power laser}

S. R. Mirfayzi, A. Alejo, H. Ahmed, D. Raspino, S. Ansell, L. A. Wilson, C. Armstrong, N. M. H. Butler, R. J. Clarke, A. Higginson, J. Kelleher, C. D. Murphy, M. Notley, D. R. Rusby, E. Schooneveld, M. Borghesi, P.

McKenna, N. J. Rhodes, D. Neely, C. M. Brenner, and S. Kar

Citation: Appl. Phys. Lett. 111, 044101 (2017); doi: 10.1063/1.4994161

View online: http://dx.doi.org/10.1063/1.4994161

View Table of Contents: http://aip.scitation.org/toc/apl/111/4

Published by the American Institute of Physics

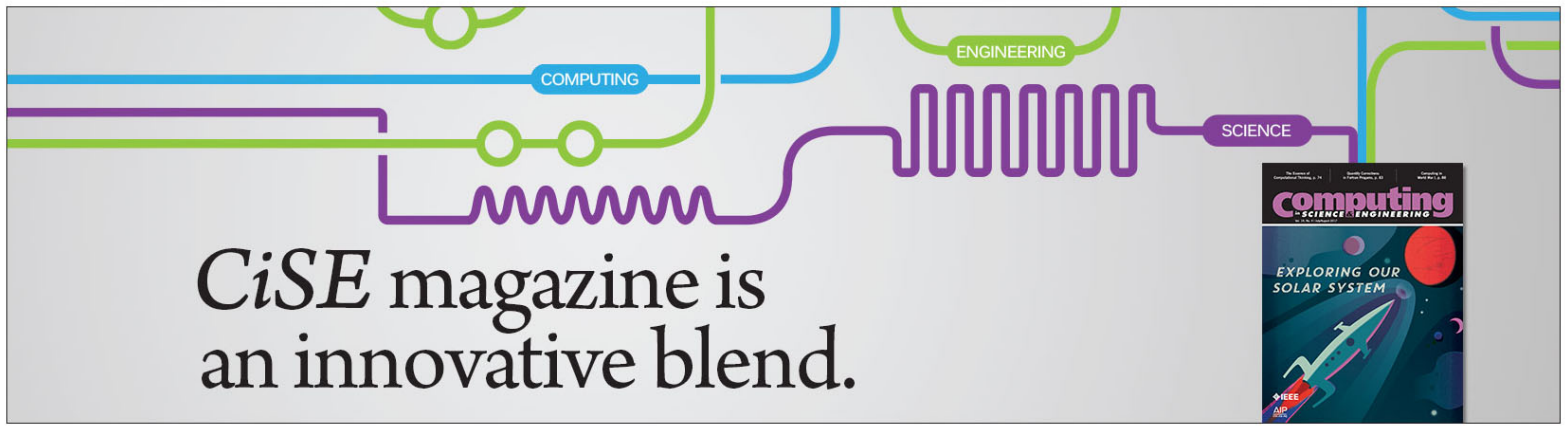




\title{
Experimental demonstration of a compact epithermal neutron source based on a high power laser
}

\author{
S. R. Mirfayzi,${ }^{1}$ A. Alejo, ${ }^{1}$ H. Ahmed, ${ }^{1}$ D. Raspino, ${ }^{2}$ S. Ansell, ${ }^{3}$ L. A. Wilson, ${ }^{4}$ \\ C. Armstrong, ${ }^{4,5}$ N. M. H. Butler, ${ }^{5}$ R. J. Clarke, ${ }^{4}$ A. Higginson, ${ }^{5}$ J. Kelleher, ${ }^{2}$ C. D. Murphy, ${ }^{6}$ \\ M. Notley, ${ }_{4}^{4}$ D. R. Rusby, ${ }^{4,5}$ E. Schooneveld, ${ }^{2}$ M. Borghesi, ${ }^{1}$ P. McKenna, ${ }^{5}$ N. J. Rhodes, ${ }^{2}$ \\ D. Neely, ${ }^{4}$ C. M. Brenner, ${ }^{4}$ and S. Kar ${ }^{1,4, a)}$ \\ ${ }^{1}$ Centre for Plasma Physics, School of Mathematics and Physics, Queen's University Belfast, Belfast BT7 INN, \\ United Kingdom \\ ${ }^{2}$ ISIS Facility, Rutherford Appleton Laboratory, Chilton, Didcot OX11 0QX, United Kingdom \\ ${ }^{3}$ European Spallation Source, 22100 Lund, Sweden \\ ${ }^{4}$ Central Laser Facility, Rutherford Appleton Laboratory, Didcot, Oxfordshire OX11 OQX, United Kingdom \\ ${ }^{5}$ Department of Physics, SUPA, University of Strathclyde, Glasgow G4 ONG, United Kingdom \\ ${ }^{6}$ Department of Physics, University of York, York YO10 5DD, United Kingdom
}

(Received 23 May 2017; accepted 4 July 2017; published online 26 July 2017)

\begin{abstract}
Epithermal neutrons from pulsed-spallation sources have revolutionised neutron science allowing scientists to acquire new insight into the structure and properties of matter. Here, we demonstrate that laser driven fast $(\sim \mathrm{MeV})$ neutrons can be efficiently moderated to epithermal energies with intrinsically short burst durations. In a proof-of-principle experiment using a $100 \mathrm{TW}$ laser, a significant epithermal neutron flux of the order of $10^{5} \mathrm{n} / \mathrm{sr} /$ pulse in the energy range of $0.5-300 \mathrm{eV}$ was measured, produced by a compact moderator deployed downstream of the laser-driven fast neutron source. The moderator used in the campaign was specifically designed, by the help of MCNPX simulations, for an efficient and directional moderation of the fast neutron spectrum produced by a laser driven source. Published by AIP Publishing. [http://dx.doi.org/10.1063/1.4994161]
\end{abstract}

Over the last few decades, there has been sustained interest in laser-driven neutron sources, which are capable of producing sub-ns bursts of fast (MeV energies) neutrons with high brightness. ${ }^{1-5}$ Although fast neutrons are useful for many applications, such as imaging ${ }^{6}$ and material testing for fusion reactor vessels, ${ }^{7}$ the arena of neutron science and applications mainly requires slow neutrons (with energies ranging from sub-meV to $\mathrm{keV}$ ) which are provided at reactor ${ }^{8}$ and accelerator ${ }^{9}$ based facilities by moderating fast neutrons. In particular, sources of epithermal neutrons $(\mathrm{eV}-100 \mathrm{keV})$ are of high interest for a wide range of applications, from material science ${ }^{10-12}$ to nuclear waste transmutations ${ }^{13}$ and healthcare. ${ }^{14,15}$ However, the scale and operational costs involved in the acceleratorbased facilities not only limit their availability to the scientific community but also hinder their wider promotion in the industrial, security, and healthcare sectors.

In this paper, we report an experimental demonstration of producing epithermal neutrons from a laser driven source. By directing the laser-driven fast neutrons produced by $\mathrm{p}-\mathrm{Li}$ reactions onto a compact $(10 \mathrm{~cm} \times 10 \mathrm{~cm} \times 8 \mathrm{~cm})$ moderator placed at $\sim 11 \mathrm{~cm}$ from the source, a significant flux of epithermal neutrons $\sim 5 \times 10^{5} \mathrm{n} / \mathrm{sr} /$ pulse in the range of $0.5-300 \mathrm{eV}$ was produced. The epithermal neutrons were measured at a distance of $2.58 \mathrm{~m}$ from the moderator using ${ }^{3} \mathrm{He}$ detectors in the time of flight (ToF) mode. The proof-ofprinciple results presented here indicate a significant scope for further improvement in terms of attainable flux by optimising the setup and the fast neutron source, as will be discussed in the concluding part of the paper. In light of the latest development in diode-pumped, high repetition rate

a)s.kar@qub.ac.uk high power laser systems, laser-based sources in the future may offer the possibility of developing compact beamlines, closely coupled to the moderator, thanks to the significantly less hostile environment offered by a laser-based system compared to reactor-based and pulsed-spallation facilities.

The experiment was carried out employing the $100 \mathrm{TW}$ arm of the VULCAN laser facility of the Rutherford Appleton Laboratory, STFC, UK. A schematic of the experimental setup is shown in Fig. 1. The $\sim 1$ ps FWHM laser pulses with an energy of $\sim 50 \mathrm{~J}$ after the compressor were focused onto $10 \mu \mathrm{m} \mathrm{Au}$ targets by an f/3 off-axis parabola, delivering peak intensities of $\sim 5 \times 10^{19} \mathrm{~W} \mathrm{~cm}^{-2}$ onto the target. The fast neutrons were produced by impinging the ions from the gold foil (henceforth called pitcher) onto a $\sim 2 \mathrm{~cm}$ thick block of lithium (henceforth called catcher), placed $\sim 5 \mathrm{~mm}$ away from the pitcher. The spectra of the fast neutrons produced at the catcher were diagnosed by a time of flight (ToF) technique, employing two fast scintillator detectors (EJ232Q ${ }^{16}$ plastic scintillator coupled to Hamamatsu R2083 PMT $^{17}$ ). As shown in Fig. 1, the detectors (henceforth called ND-1 and ND-2, respectively) were located at $4.37 \mathrm{~m}$ and $4.27 \mathrm{~m}$ from the source, respectively, measuring fast neutrons spectra along the lines $0^{\circ}$ (on axis) and $35^{\circ}$ (off axis) with respect to the ion beam axis. The scintillator detectors were absolutely calibrated for fast neutrons, as reported in Ref. 18.

After characterising the fast neutron spectra along $0^{\circ}$ and $35^{\circ}$, a pair of Reuter Stokes ${ }^{3} \mathrm{He}$ filled (at 10 bars pressure) proportional counters ${ }^{19}$ were placed along the beam axis. The ${ }^{3} \mathrm{He}$ detectors were placed inside a shielded housing with high voltage $(2 \mathrm{kV})$ applied across their anodes and cathodes. Due to the high sensitivity of the ${ }^{3} \mathrm{He}$ detectors, the 

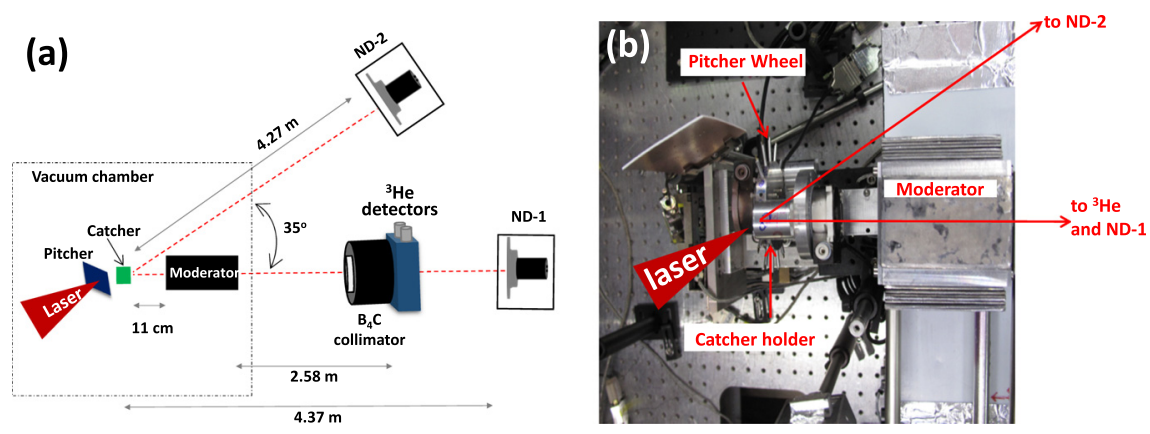

FIG. 1. (a) Schematic of the experimental setup (figure not to scale). (b) Image of the setup inside the interaction chamber. The fast neutrons were generated by nuclear reactions in the catcher target, induced by the $\mathrm{MeV}$ ions accelerated from the laser irradiated pitcher target. ND-1 and ND-2 are EJ232Q scintillator detectors, placed inside lead $\left(5 \mathrm{~cm}\right.$ thick) and plastic $\left(5 \mathrm{~cm}\right.$ thick) housings, employed in the ToF mode to diagnose the fast neutron spectra. ${ }^{18}$ Epithermal neutrons produced by the moderator were diagnosed by the ${ }^{3} \mathrm{He}$ proportional counters employed in the ToF mode, placed behind a $\mathrm{B}_{4} \mathrm{C}$ collimator.

gamma flash produced by the laser interaction saturated the signal at early times, and only neutrons of energy up to $\sim 300 \mathrm{eV}$ could be detected by the ${ }^{3} \mathrm{He}$ detectors in a ToF mode. The efficiency of the detectors with respect to the incident neutron energy is given by the formula, $\eta=1-$ $\exp (-0.00482 P d \lambda)$, where $P$ is the gas pressure in bar, $d$ is the tube diameter in $\mathrm{mm}$, and $\lambda$ is the wavelength of neutrons in angstroms. One of the ${ }^{3} \mathrm{He}$ detectors was wrapped with a few $\mathrm{mm}$ thick cadmium sheets in order to identify the background level of stray thermal $[\leq 0.5 \mathrm{eV}$ (Ref. 20)] neutrons hitting the detector. The ${ }^{3} \mathrm{He}$ detectors were placed behind a $\mathrm{B}_{4} \mathrm{C}$ cylindrical collimator $(\sim 30 \mathrm{~cm}$ long with an outer diameter of $\sim 30 \mathrm{~cm}$ and an inner diameter of $\sim 5 \mathrm{~cm}$ ) as shown in Fig. 1.

The configuration of the compact moderator used in the experiment is shown in Fig. 2(a). The fast neutrons from the catcher were directed to impinge onto the moderator, which was aligned along the beam axis as shown in Fig. 1. The thickness and materials used in the moderator were chosen based on Monte Carlo N-Particle eXtended (MCNPX) ${ }^{21}$ simulations, with the aim of optimizing the flux of epithermal neutrons from the exit plane of the moderator. The choice of materials for the experiment was restricted by radiation safety and manufacturing constraints. Within the overall moderator size, the main component was a $5 \mathrm{~cm} \times 5 \mathrm{~cm} \times 4 \mathrm{~cm}$ block of high density polystyrene, which was designed to slow down $\sim \mathrm{MeV}$ neutrons to the epithermal range [mean free path of $1 \mathrm{MeV}$ neutron is $\sim 3 \mathrm{~cm}$ (Ref. 22)]. Under the condition of the experiment, the high $Z$ front layers $(2.4 \mathrm{~cm}$ thick lead and $1.2 \mathrm{~cm}$ thick tungsten) mainly served as reflectors to the moderated neutrons produced by the polystyrene block. However, in the presence of higher energy $(\geq 10 \mathrm{MeV})$ neutrons, this design would also increase the neutron population by $(\mathrm{n}, \mathrm{xn})$ reactions inside the thick layers of lead and tungsten. The polystyrene, tungsten, and lead blocks were housed in a cm-thick aluminium structure, surrounded by $1.5 \mathrm{~cm}$ thick lead to reduce neutron leakage from the side walls of the moderator. In order to produce a pure epithermal beam and filter the lower energy neutrons, a $2 \mathrm{~mm}$ cadmium sheet was placed at the exit plane of the moderator.

As can be seen in Fig. 2(a), the moderator produces an anisotropic flux distribution of epithermal neutrons. While the front layers of lead and tungsten may contribute by premoderating and multiplying high energy neutrons, the sub$\mathrm{MeV}$ neutrons are efficiently moderated to the epithermal range inside the polystyrene block. The neutron spectra emerging from the exit plane and the side of the moderator for different input neutron energies are shown in Fig. 2(b), which illustrates the effectiveness of the design in moderating neutrons of $\mathrm{MeV}$ energies, as produced in abundance in our experiment [see Fig. 3(a)].

The experiment was carried out in two stages. Since the moderator and the ${ }^{3} \mathrm{He}$ detector restrained us from measuring the fast neutrons produced along the beam axis, the first stage was devoted for characterising spectra and angular distribution of the fast neutrons produced by the catcher, before deploying the moderator and the ${ }^{3} \mathrm{He}$ detectors. The data collected by the two scintillator detectors over a number of dedicated shots showed fairly similar spectral profiles as shown
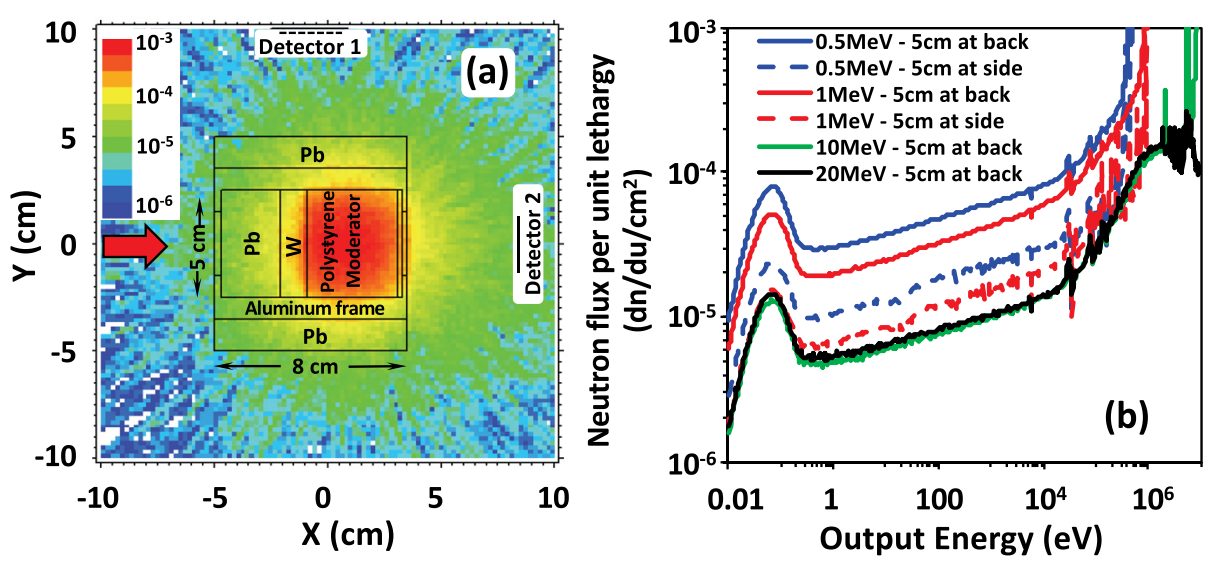

FIG. 2. (a) The design of the moderator superimposed on the neutron (in the range of $1 \mathrm{eV}-1 \mathrm{keV}$ ) flux distribution across the mid-plane of the moderator, obtained from MCNPX simulation for $1 \mathrm{MeV}$ neutrons entering the moderator from the left side (shown by red arrow). (b) Comparison between neutron spectra at the two detectors, detector-1 and detector-2, respectively [shown in (a)], placed $5 \mathrm{~cm}$ away from the side and exit faces of the moderator for different incident neutron energies as obtained from MCNPX simulations. 

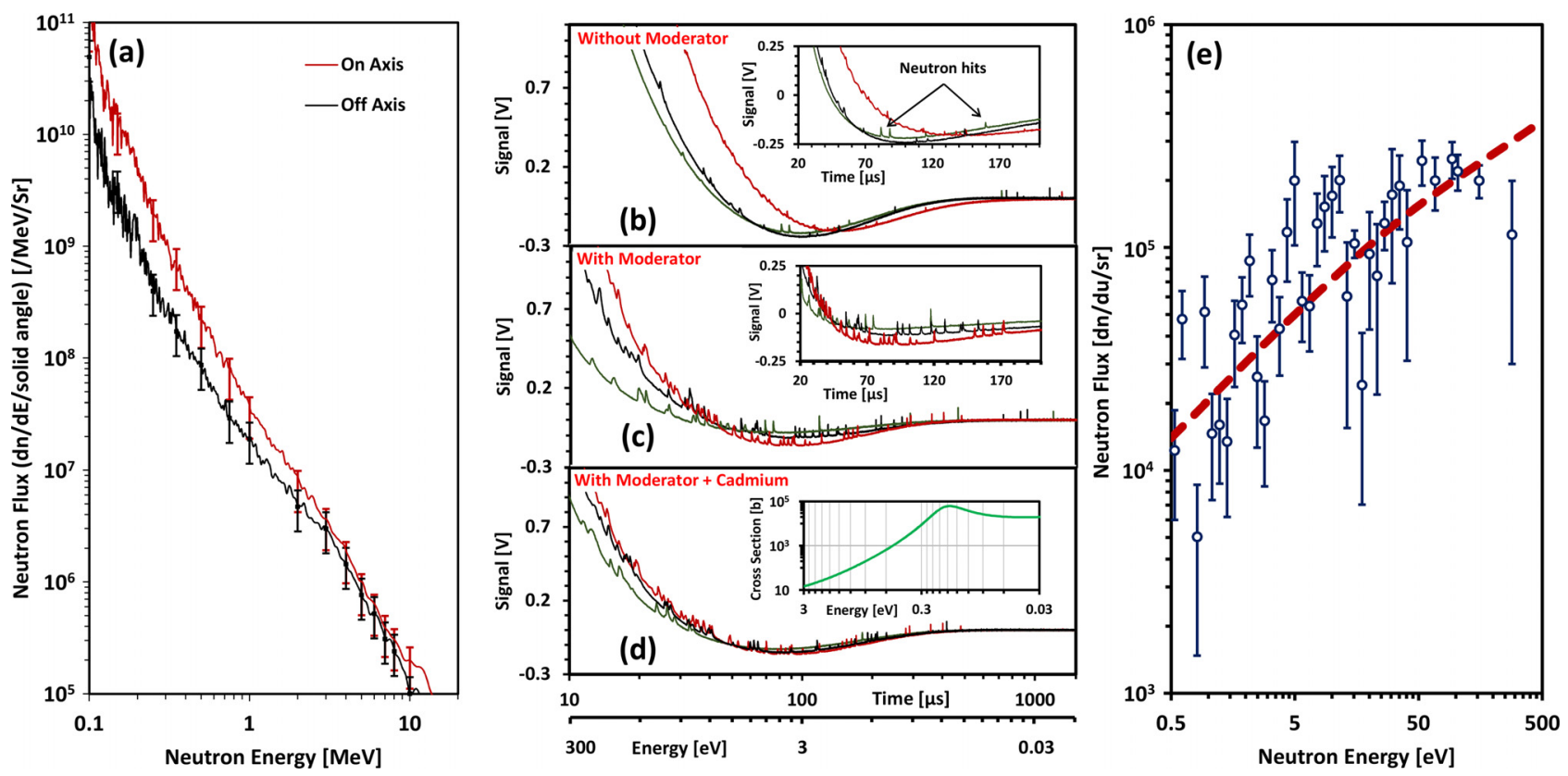

FIG. 3. (a) Typical spectra of fast neutrons produced in the experiment, as measured by the ND-1 (on-axis) and ND-2 (35 off axis) detectors. (b) and (c) Raw data (from three shots for each case) obtained in the ${ }^{3} \mathrm{He}$ detectors without and with the moderator, respectively. (d) Raw data in the presence of the moderator obtained in the ${ }^{3} \mathrm{He}$ detectors wrapped with $\mathrm{Cd}$ foil, which is a good absorber of neutrons of energies below $\sim 0.5 \mathrm{eV}$, as can be seen from the cross-section of ${ }^{113} \mathrm{Cd}(\mathrm{n} \text {, total })^{20}$ plotted in the inset. The zoomed plots of the raw data on the linear X-scale are shown in the insets. Epithermal neutron hits are identified by the voltage spikes in the output signal [as shown in the inset in (b)] and the neutron energy is calculated by ToF [as shown in a separate axis under (d)]. (e) Epithermal neutron spectra produced by the moderator, averaged over 16 measurements, where the red line is an eye-guide to the data points.

in Fig. 3(a). The neutron flux above $2.5 \mathrm{MeV}$ was measured to be $\sim 10^{7} \mathrm{n} / \mathrm{Sr}$, whereas the spectra indicate that the highest flux lies in the sub-MeV region (estimated to be of the order of $10^{9} \mathrm{n} / \mathrm{sr}$ between 0.1 and $1 \mathrm{MeV}$ ). The ratio of the fast neutron fluxes recorded by ND-1 and ND-2 was found to be $\sim 0.6$ over a number of shots taken at similar laser and pitcher/catcher conditions. When the ND-1 became redundant in the following stage (due to the installation of the onaxis ${ }^{3} \mathrm{He}$ detector, see Fig. 1), the data obtained by the ND-2 were used as a reference to infer the on-axis fast neutron spectra.

Placing the moderator at a distance of $\sim 11 \mathrm{~cm}$ behind the catcher produced a significant amount of epithermal neutrons along the beam axis, in contrast to what detected in shots without the moderator. This is apparent from the increased number of voltage spikes in the voltage versus time/energy plots of Figs. 3(c) and 3(d), compared to the plot of Fig. 3(b). Each voltage spike is created when a neutron is absorbed in the ${ }^{3} \mathrm{He}$ detector via the ${ }^{3} \mathrm{He}(\mathrm{n}, \mathrm{p}){ }^{3} \mathrm{H}$ reaction, and the released proton and ${ }^{3} \mathrm{H}$ ionize the gas inside the detector generating an electron avalanche. While the incident neutron energy was determined from the ToF, the neutron flux was calculated by counting the number of voltage spikes in the output signal. As expected, the $\mathrm{Cd}$ wrapped ${ }^{3} \mathrm{He}$ detector showed rapidly decreasing number of neutron hits in the signal trace after $\sim 300 \mu \mathrm{s}$, as shown in Fig. 3(d), which is consistent with the absorption cross-section of $\mathrm{Cd}$ for low energy neutrons. Taking into account the detector efficiency (as mentioned earlier) and normalising the signal with respect to the incident neutron flux measured by the ND-2 detector in the same shot, the spectrum of the epithermal neutrons was obtained. Figure 3(e) shows the epithermal neutron spectrum produced by the moderator in the detectable energy range of $0.5-300 \mathrm{eV}$, by averaging over 8 shots (i.e., 16 measurements). The high energy cut-off is due to the saturation of the ${ }^{3} \mathrm{He}$ detectors at early times by the gamma flash. As can be seen in Fig. 3(b), the number of neutron hits within the detectable energy range was insignificant in shots without the moderator. The backgroundsubtracted neutron flux produced by the moderator in the energy range of $0.5-300 \mathrm{eV}$ was $(5.1 \pm 0.15) \times 10^{5} \mathrm{n} / \mathrm{sr} /$ pulse.

As mentioned earlier, the experiment was designed to assess and demonstrate the feasibility of driving intense bursts of epithermal neutrons with short pulse lasers. The moderator in the current experiment was placed at a distance of $\sim 11 \mathrm{~cm}$ from the catcher to monitor shot-to-shot variations in the fast neutron spectra by the ND-2. If the moderator were placed in contact with the catcher, using a minimal $(\sim \mathrm{cm})$ thickness of high $\mathrm{Z}$ material in its front layer, the fast neutron flux per $\mathrm{cm}^{2}$ incident on the polystyrene would have increased by two orders of magnitude, producing a commensurate increase in epithermal flux at the moderator output. A prudent estimation based on MCNPX simulations suggests that an epithermal flux of $\sim 10^{4} \mathrm{n} / \mathrm{cm}^{2} /$ pulse in the energy range of $0.5-300 \mathrm{eV}$ $\left(\sim 3 \times 10^{4} \mathrm{n} / \mathrm{cm}^{2} /\right.$ pulse for $\left.1 \mathrm{eV}-100 \mathrm{keV}\right)$ was produced in the current experiment at a nominal distance of $5 \mathrm{~cm}$ from the moderator [i.e., at the detector-2 position in Fig. 2(a)].

While these proof-of-principle results are encouraging, there is significant scope for further optimisation of the epithermal neutrons flux by optimising the moderator design as well as the fast neutron source. The input flux of fast neutrons can be significantly enhanced by increasing the energy and number of incident ions on the catcher. Order of magnitude higher fast neutron fluxes than produced in the current experiment have been already reported, ${ }^{2-4}$ and, in 
principle, can be further improved upon by taking advantage of ongoing developments in laser-driven ion acceleration. ${ }^{23-25}$ A credible source of fast neutrons can also be obtained by deploying $\mathrm{MeV}$ electron jets from laser-driven exploding foils. ${ }^{5}$ High energy electrons efficiently produce neutrons inside a metal converter via photo-nuclear reactions by generating high flux of bremsstrahlung photons. Albeit isotropic, such sources produce neutrons of energy in the $\mathrm{MeV}$ range, highly desirable for moderation. In terms of optimising the moderation process, laser driven sources offer greater flexibility compared to the other facilities, where the formidable heat and extraneous radiations constrain significantly the choice of material, temperature, and geometry of a moderator. Finally, it is to be noted that the epithermal bursts produced by the laser-driven neutrons of sub-ns duration would also have an intrinsically short duration (solely determined by the characteristics of the moderator), beyond the capability of the accelerator-driven spallation sources, typically set by the duration (sub$\mu \mathrm{s}-\mathrm{ms}$ ) of their proton pulses. ${ }^{26-28}$

Laser-based sources are fast approaching a crucial stage in their development for neutron science and applications to complement large-scale facilities. Although sources such as the National Ignition Facility report record yield in fusion neutrons per pulse, ${ }^{29,30}$ its scale and repetition rate are inadequate for any credible application related to neutron science. On the other hand, the repetition rates achievable on smaller scale installations could still be too low to guarantee successful exploitation for the aforementioned applications. The future of a laser-based approach would be reliant on the progress in diode-pumped technologies, such as the DiPOLE $^{31,32}$ and HAPLS ${ }^{33}$ projects, aiming towards developing $10 \mathrm{~Hz}$, Petawatt-class laser systems.

We acknowledge funding from EPSRC [EP/J002550/1Career Acceleration Fellowship held by S.K., EP/L002221/1, EP/J500094/1, EP/K022415/1, and EP/J003832/1] and STFC [ST/P000142/1]. This work was also supported by STFC's Business and Innovation Directorate. Authors would like to acknowledge valuable discussions with J. Collier (Director of CLF, STFC, UK), S. Langridge (Head of diffraction and materials division, ISIS, STFC, UK), and R. Dalgliesh (Instrument Scientist, ISIS, STFC, UK). Authors also acknowledge support from A. Cox (mechanical engineering) and D. Haddock (target fabrication group) of the CLF, STFC, UK. Data associated with the research published in this article can be accessible at http://dx.doi.org/10.17034/d3a467ee-2fb14825-9a35-1bbb46207ca8.

${ }^{1}$ T. Ditmire, J. Zweiback, V. P. Yanovsky, T. E. Cowan, G. Hays, and K. B. Wharton, Nature 398, 489 (1999).

${ }^{2}$ M. Roth, D. Jung, K. Falk, N. Guler, O. Deppert, M. Devlin, A. Favalli, J. Fernandez, D. Gautier, M. Geissel et al., Phys. Rev. Lett. 110, 044802 (2013).

${ }^{3}$ S. Kar, A. Green, H. Ahmed, A. Alejo, A. P. L. Robinson, M. Cerchez, R. Clarke, D. Doria, S. Dorkings, J. Fernandez et al., New J. Phys. 18, 053002 (2016).

${ }^{4}$ A. Alejo, A. G. Krygier, H. Ahmed, J. T. Morrison, R. J. Clarke, J. Fuchs, A. Green, J. S. Green, D. Jung, A. Kleinschmidt et al., Plasma Phys. Controlled Fusion 59, 064004 (2017).
${ }^{5}$ I. Pomerantz, E. McCary, A. R. Meadows, A. Arefiev, A. C. Bernstein, C. Chester, J. Cortez, M. E. Donovan, G. Dyer, E. W. Gaul et al., Phys. Rev. Lett. 113, 184801 (2014).

${ }^{6}$ A. Buffler, Rad. Phys. Chem. 71, 853 (2004).

${ }^{7}$ L. J. Perkins, B. G. Logan, M. D. Rosen, M. D. Perry, T. Diaz de la Rubia, N. M. Ghoniem, T. Ditmire, P. T. Springer, and S. C. Wilks, Nucl. Fusion 40, 1 (2000).

${ }^{8}$ See http://www.ga.com/triga for information about TRIGA reactor neutron source; see https://www.ill.eu for information about ILL high flux reactor.

${ }^{9}$ See http://www.isis.stfc.ac.uk for information about ISIS pulsed neutron; see https://neutrons.ornl.gov/sns for information about Spallation Neutron Source and the High Flux Isotope Reactor at Oak Ridge National Laboratory; see https://europeanspallationsource.se for information about European Spallation Source.

${ }^{10}$ R. Senesi, A. Pietropaolo, A. Bocedi, S. E. Pagnotta, and F. Bruni, Phys. Rev. Lett. 98, 138102 (2007).

${ }^{11}$ C. A. Chatzidimitriou-Dreismann and I. C. Tietje, J. Phys. Conf. Ser. 237, 012010 (2010).

${ }^{12}$ E. P. Cippo, A. Borella, G. Gorini, W. Kockelmann, M. Moxon, H. Postma, N. J. Rhodes, P. Schillebeeckx, E. M. Schoonenveld, M. Tardocchi et al., J. Anal. At. Spectrom. 26, 992 (2011).

${ }^{13}$ E. Mendoza, D. Cano-Ott, C. Guerrero, E. Berthoumieux, U. Abbondanno, G. Aerts, F. Álvarez-Velarde, S. Andriamonje, J. Andrzejewski, P. Assimakopoulos, L. Audouin et al., Phys. Rev. C 90, 034608 (2014).

${ }^{14}$ N. Burgio, L. Maciocco, K. Abbas, F. Simonelli, A. Santagata, S. Buono, N. Gibson, G. Cotogno, I. Cydzik, U. Holzwarth et al., IEEE Trans. Nucl. Sci. 58, 445 (2011).

${ }^{15}$ R. Terlizzi, N. Colonna, P. Colangelo, A. Maiorana, S. Marrone, A. Rainó, G. Tagliente, and V. Variale, Appl. Radioact. Isot. 67, S292 (2009).

${ }^{16}$ See http://www.eljentechnology.com for information about EJ-232Q crystal.

${ }^{17}$ See http://www.hamamatsu.com/jp/en/R2083.html for information about R2083 Hamamatsu photomultiplier tube.

${ }^{18}$ S. R. Mirfayzi, S. Kar, H. Ahmed, A. G. Krygier, A. Green, A. Alejo, R. Clarke, R. R. Freeman, J. Fuchs, D. Jung et al., Rev. Sci. Instrum. 86, 073308 (2015).

${ }^{19} \mathrm{GE}$ Reuter Stokes, https://www.gemeasurement.com/ for Helium-3 neutron detector.

${ }^{20}$ See https://www-nds.iaea.org/exfor/endf.htm for information on cadmium capture cross-section.

${ }^{21}$ D. B. Pelowitz, MCNPX User's Manual Version 2.5.0. (Los Alamos National Laboratory, 2005), Vol. 76.

${ }^{22}$ W. J. Nellis, Am. J. Phys. 45, 443 (1977).

${ }^{23}$ A. Macchi, M. Borghesi, and M. Passoni, Rev. Mod. Phys. 85, 751 (2013).

${ }^{24}$ F. Wagner, O. Deppert, C. Brabetz, P. Fiala, A. Kleinschmidt, P. Poth, V. A. Schanz, A. Tebartz, B. Zielbauer, M. Roth et al., Phys. Rev. Lett. 116, 205002 (2016).

${ }^{25}$ S. Kar, K. F. Kakolee, B. Qiao, A. Macchi, M. Cerchez, D. Doria, M. Geissler, P. McKenna, D. Neely, J. Osterholz et al., Phys. Rev. Lett. 109, 185006 (2012).

${ }^{26}$ N. Watanabe, Rep. Prog. Phys. 66, 339 (2003).

${ }^{27}$ E. V. Iverson, B. J. Micklich, and J. M. Carpenter, KEK Proc. Vol. 2, High Energy Accel. Res. Org. 6-9, 1372 (1999-2000), available at https://inis. iaea.org/search/search.aspx?orig_q=RN:43009536.

${ }^{28}$ K. Kino, M. Furusaka, F. Hiraga, T. Kamiyama, Y. Kiyanagi, K. Furusaka, S. Goko, K. Y. Hara, H. Harada, M. Harada et al., Nucl. Instrum. Methods A 736, 66 (2014).

${ }^{29}$ A. Taylor, M. Dunne, S. Bennington, S. Ansell, I. Gardner, P. Norreys, T. Broome, D. Findlay, and R. Nelmes, Science 315, 1092 (2007).

${ }^{30}$ T. Döppner, D. A. Callahan, O. A. Hurricane, D. E. Hinkel, T. Ma, H.-S. Park, L. F. Berzak Hopkins, D. T. Casey, P. Celliers, E. L. Dewald et al., Phys. Rev. Lett. 115, 055001 (2015).

${ }^{31}$ S. Banerjee, K. Ertel, P. D. Mason, P. J. Phillips, M. De Vido, J. M. Smith, T. J. Butcher, C. Hernandez Gomez, R. J. S. Greenhalgh, and J. L. Collier, Opt. Express 23, 19542 (2015).

${ }^{32}$ S. Banerjee, P. D. Mason, K. Ertel, P. J. Phillips, M. De Vido, O. Chekhlov, M. Divoky, J. Pilar, J. M. Smith, T. J. Butcher et al., Opt. Express 41, 2089 (2016).

${ }^{33} \mathrm{See}$ https://lasers.llnl.gov/science/photon-science/highpowered-lasers for information on HAPLS. 